\title{
Receptor-Type Tyrosine-Protein Phosphatase Delta
}

National Cancer Institute

\section{Source}

National Cancer Institute. Receptor-Type Tyrosine-Protein Phosphatase Delta. NCI

Thesaurus. Code C106112.

Receptor-type tyrosine-protein phosphatase delta (1912 aa, $\sim 215 \mathrm{kDa}$ ) is encoded by the human PTPRD gene. This protein is involved in both dendrite morphogenesis and phosphotyrosine dephosphorylation. 